\title{
Problemática ambiental ou problemática socioambiental? A natureza da relação sociedade/meio ambiente
}

\author{
An environmental or a socio-environmental issue? \\ The nature of the society-environment relationship
}

\author{
Valdir FERNANDES* \\ Carlos Alberto Cioce SAMPAIO**
}

\begin{abstract}
RESUMO
A problemática socioambiental postula uma mudança de paradigma que tem como base de sustentação uma racionalidade alternativa aos grandes conflitos da sociedade moderna. Esses conflitos são traduzidos e resumidos pela difícil relação entre desenvolvimento econômico e preservação ambiental. A mudança de paradigma está no fato de inserir a sustentabilidade socioambiental como critério de desenvolvimento. A problemática socioambiental postula também outra abordagem epistemológica por intermédio da visão sistêmica e da atuação interdisciplinar, apoiada numa mudança moral e ética. O objetivo deste ensaio é discorrer sobre esses postulados de mudança e sobre a dicotomia entre sistemas ecológicos e sociais.
\end{abstract}

Palavras-chave: problemática socioambiental; sustentabilidade; interdisciplinaridade; paradigma.

\begin{abstract}
The socio-environmental debate postulates a paradigm shift that is sustained by a kind of rationality that serves as an alternative to the big conflicts of modern society. These conflicts have to do with the difficult relationship between economic development and environmental preservation. The paradigm shift consists in including socio-environmental sustainability as a pre-requisite for development. The socio-environmental debate also postulates another epistemological approach through a systemic vision and inter- and trans-disciplinary action, propped up by moral and ethical change. The purpose of this paper is to discuss these change postulates, while undoing the dichotomy between ecological and social systems.
\end{abstract}

Key words: socio-environmental issue; sustainability; interdisciplinarity; paradigm.

\footnotetext{
"Cientista Social, doutor em gestão ambiental pela Universidade Federal de Santa Catarina. Atualmente vinculado ao Departamento de Saúde Ambiental, Faculdade de Saúde Pública da Universidade de São Paulo (USP), onde realiza estágio de pós-doutorado.Contato: v.fernandes@usp.br; valdir@fidata.com.br.

** Professor do Doutorado em Ciências Contábeis e Administração e do Mestrado em Desenvolvimento Regional da Universidade Regional de Blumenau (FURB). Coordenador do Instituto LaGOE: Laboratório de Gestão Organizacional que promove o Ecodesenvolvimento (ONG situada em Curitiba). Pesquisador do Instituto de Economia da Universidade Austral do Chile. Contato: sampaio@furb.br ou sampaio@lagoe.org.br.
} 


\section{Introdução}

Thomas Khun (1996) define paradigma como "as realizações científicas universalmente reconhecidas que, durante algum tempo, fornecem problemas e soluções modelares para uma comunidade de praticantes de uma ciência”. A noção de paradigma de Kuhn (MORIN, 2000) é uma espécie de revolucionismo que se contrapõe ao evolucionismo teórico de Popper. Kuhn diferencia "ciência normal", quando o paradigma dominante ainda responde aos fenômenos existentes, de "ciência extraordinária", quando o paradigma dominante não responde aos novos fenômenos. Porém, mesmo na ciência definida como normal, existe uma revolução científica permanente. A ciência está sempre em movimento, em ebulição, e talvez o próprio fundamento de sua atividade é ser impulsionada por poder de transformação. Disto se conclui que é ingênua a idéia de que há um progresso linear das teorias que se aperfeiçoam mutuamente (MORIN, 2000). A ciência define-se pela incerteza e não pela certeza, e a teoria científica é uma construção que depende essencialmente do diálogo com o mundo dos fenômenos e não está desligada dos elementos culturais, sociológicos, econômicos e espirituais presentes na sociedade. O paradigma científico não está desconectado do paradigma predominante na sociedade, porque a ciência não está desligada da sociedade, da cultura, da natureza. Ela produz e se reproduz para e a partir destas realidades naturais, culturais e sociológicas. Um paradigma pode ser definido, assim, como um conjunto de valores e regras socioculturais universalmente aceitos por algum tempo em uma sociedade ou grupo cultural, moldando e conduzindo as suas práticas.

Os paradigmas não duram eternamente, havendo de tempos em tempos a transição de um paradigma para outro. Essa transição, segundo Santos (2000) ocorre por meio de lutas subparadigmáticas que trazem em si, por um lado, a crença na hipótese de que o paradigma dominante possa dar respostas adequadas aos problemas por ele gerados, e, por outro lado, o surgimento de alternativas a esse mesmo paradigma. Para que ocorra a emergência de um novo paradigma é necessário que a ausência das lutas subparadigmáticas se consolide e se abdique do paradigma anterior em favor do novo paradigma. Essa transição é uma passagem e, como tal, não se pode definir ao certo o momento em que se vive no novo ou no antigo paradigma; isso porque a morte de um paradigma só pode ser confirmada depois de anos ou, às vezes, até mesmo séculos da sua morte. "Ao contrário do que se passa com a morte dos indivíduos, a morte de um dado paradigma traz dentro de si o paradigma que lhe há de suceder" (SANTOS, 2000, p. 15).

A partir dessa sumária definição de paradigma, pode-se afirmar que vivemos numa época de crises e que, embora não se possa afirmar ao certo seu futuro, pode-se dizer ao certo sua origem: uma profunda crise de valores, de conceitos e de projetos, da qual a crise ambiental é uma das maiores expressões. O paradigma atual (colonialista, civilizatório, progressista, economicista) gerou uma série de problemas, os quais não é capaz de resolver.

Dentre as equações insolúveis está o fato de que a economia, que deveria ser apenas um subsistema da biosfera ${ }^{1}$, tornou-se o seu determinante maior. No paradigma atual, aposta-se sempre no crescimento econômico como resolução dos problemas socioambientais decorrentes do próprio economicismo. A racionalidade econômica, que, por muito tempo, ignorou os problemas ambientais, mais recentemente tem tentado incorporar a destruição da natureza nos preços dos produtos, mas sem o estabelecimento de uma escala para o crescimento da economia - que historicamente desconsidera os limites biofísicos. Isto é, a chamada ecoeficiência, baseada no princípio poluidor-pagador. Contudo, não repensa a racionalidade vigente por trás do processo decisório quando se implementa um estilo de planejamento e de gestão organizacional, mesmo se conectado à perspectiva do desenvolvimento sustentável (ALIER, 2007).

Diante do último relatório do Intergovernmental Panel of Climate Change (IPCC), divulgado em 2007, formulado pela World Meteorological Organization, WMO, no âmbito do United Nations Environmental Programme, UNEP, mesmo os mais céticos economicistas não conseguem mais ficar indiferentes a tais prognósticos. Este relatório revela que a mudança climática em curso tem como

'O termo "biosfera" foi introduzido em 1875 pelo geólogo austríaco Eduard Suess (1831-1914), durante uma discussão sobre os vários envoltórios da Terra. Em 1926 e 1929, o mineralogista russo Vladimir Vernandsky (1863-1945) consagrou definitivamente o termo, utilizando-o em duas conferências de sucesso. 
principal causa a ação antrópica (referenciando a emissão de gases de efeito estufa, sendo o mais importante o dióxido de carbono, que responde por $80 \%$ do total das emissões lançadas na atmosfera quando se queimam combustíveis fósseis, petróleo, gás natural e carvão), sobretudo após a revolução industrial (WMO-UNEP, 2007).

Além disso, não foram respeitados dois pressupostos básicos para manter a dinâmica natural: não retirar dos ecossistemas mais do que sua capacidade de regeneração; não lançar aos ecossistemas mais do que a sua capacidade de absorção. Não se levou em conta que "a biosfera não 'cresce' e é a fonte de todos os materiais que alimentam a economia, e lugar de despejo dos seus rejeitos" (MERICO, 1996, p. 30). Como pensar então em um crescimento econômico infinito? A crise do paradigma vigente, no que concerne à concepção desenvolvimentista voltada essencialmente para a expansão das fronteiras econômicas, está, portanto, no fato de que ele esgota simultaneamente suas próprias fontes de riqueza e de sustentação.

A partir dessas evidências, a crise do paradigma desenvolvimentista deve ser definida também em suas dimensões morais, somando-se às análises científicas e econômicas. De acordo com Dansereau (1999), a condição prévia para o entendimento da dimensão moral desta crise é a prospecção ecológica. Em suas afirmações, está presente o entendimento de que a raiz de grande parte dos problemas hoje vividos é ao mesmo tempo causa e conseqüência da crise de valores e moral ocasionada pelo predomínio de valores fragmentados e não ecológicos, fundamentados no dualismo e na dicotomia e típicos das sociedades ocidentais capitalistas. A prescrição moral vigente não advém da prescrição ecológica. Por esse motivo, os riscos de ultrapassagem irreversíveis dos limites biosféricos ainda são pouco percebidos, e há uma crise de consciência dos problemas gerados pela ação antrópica e suas conseqüências na natureza (MORIN; KERN, 1995).

A crise de paradigma atual é, assim, uma crise da relação sociedade/natureza, e as suas causas estão no modo de vida centrado na idéia de progresso e colonização. Colonização do futuro e colonização da natureza, em detrimento da unidade e da co-evolução entre os sistemas sociais e naturais (KоTHARI, 1990). Daí a importância de se explorar a problemática ambiental de maneira a fazer compreensível a sua articulação com os problemas socioeconômicos e com o modo de vida capitalista, arraigado culturalmente na sociedade atual.
O objetivo deste ensaio é abordar esta problemática a partir de um enfoque socioambiental, buscando uma leitura além da dicotomia entre sistemas ecológicos e sociais. A problemática ambiental como uma problemática eminentemente social.

\section{Problemática socioambiental}

A problemática ambiental, que começou a ser percebida a partir da década de 1960, é, atualmente, amplamente discutida, principalmente nos meios acadêmicos, como relacionada ao modo de vida das sociedades ocidentais, no que se refere à produção e consumo e, portanto, aos problemas sociais e econômicos. É construída e definida teoricamente, nos meios acadêmicos, como uma problemática eminentemente social que surge da forma como a sociedade se relaciona com a natureza - a problemática ambiental como problemática econômica, social, cultural e espiritual, dependendo da corrente teórica e acadêmica.

Nessa perspectiva, é possível afirmar que a natureza não tem problemas e, se os tem, são inerentes a sua dinâmica e resolvidos por ela. A definição de problemática ambiental, portanto, é uma definição diretamente ligada às atividades sociais que incidem sobre a natureza.

Para situar de maneira mais precisa esta discussão, recorre-se ao que afirma Serres: "Passa-se com a Terra na sua totalidade o mesmo que acontece com os homens no seu conjunto (...)", não são coisas separadas, mas faces de uma mesma moeda (SERRES, 2000, p. 16). Desequilíbrio social e desequilíbrio ambiental são problemas que têm a mesma origem: a racionalidade predominantemente econômica. Estamos embarcados numa aventura econômica, científica e tecnológica que é irreversível (SERRES, 2000, p. 17); contudo, o crescimento econômico, embora necessário, não é condição suficiente para um desenvolvimento equilibrado. A questão que se coloca, porém, é: por que é tão difícil fazer essas conexões no mundo da vida?

Disse-se que os problemas ambientais surgem do modo como a sociedade relaciona-se com a natureza. O que faltou dizer é que essa relação com a natureza nada mais é do que parte da relação que se estabelece entre as sociedades e entre os indivíduos. A relação desequilibrada que se mantém com a natureza - na medida que se retira dela mais do que a sua capacidade de regeneração e se lança a ela 
mais do que a sua capacidade de absorção - nada mais é do que o resultado da relação desequilibrada que se estabeleceu entre os seres humanos. Habitualmente, atribuímos a essa relação os problemas sociais e econômicos, mas não os problemas ambientais. No entanto, a raiz dos problemas sociais e econômicos é a mesma dos problemas ambientais, como evidenciado por Horkheimer:

A moderna insensibilidade para com a natureza é de fato apenas uma variação da atitude pragmática que é típica da civilização ocidental como um todo [...]. A história dos esforços para subjugar a natureza é também a história da subjugação do homem pelo homem [...]. O conflito entre os homens na guerra e na paz é a chave da insaciabilidade da espécie e das atitudes práticas resultantes disso, bem como das categorias e métodos da inteligência científica, nos quais a natureza aparece cada vez mais sob o aspecto de sua exploração eficaz. Essa forma de percepção determinou também o modo pelo qual os seres humanos se concebem reciprocamente nas suas relações econômicas e políticas (HORKHEIMER, 2002, p. 108, 112).

Nesse sentido, a problemática ambiental enceta uma crise muito maior que a destruição da natureza. Ela é expressão de uma crise muito mais ampla, cujo cerne está na sociedade e no modo de vida essencialmente voltado para fins econômicos. As relações sociedade/natureza, que, na ciência positivista, supunham compreender e modificar na sociedade como um todo, incluindo a ciência, implicam interações muito mais amplas e com conseqüências muito menos controláveis do que aquelas pressupostas nas duas dimensões previstas na ciência positivista (PRIGOGINE; STENGERS, 1984).

Como preconizam Maturana e Varela (2001), a pluralidade da problemática ambiental está longe de se restringir apenas à relação dual sociedade/natureza. Essa visão é compartilhada por outros autores como Morin, Santos, Prigogine e Sachs, reforçando a contradição de que o atual sistema socioeconômico esgota simultaneamente suas próprias fontes de riqueza e de sustentação: o homem e a natureza (ANTUNES, 1990).
Trata-se de uma característica do tipo de desenvolvimento adotado a partir do século XVIII. Desenvolvimento baseado na racionalidade predominantemente econômica, a Razão Moderna, na qual o desenvolvimento é sinônimo de crescimento econômico (MORIN; KERN, 1995). Essa racionalidade, entretanto, é míope em relação aos problemas socioambientais decorrentes dela. Ironicamente, não podemos prescindir dos benefícios econômicos proporcionados pela economia, mesmo que, na sua maioria, esses benefícios sejam inatingíveis, além de, muitas vezes, representarem um custo ambiental inestimável e incalculável. O meio ambiente, que é, em última análise, um único todo chamado Terra, sofreu, a partir dos modernos, um processo crescente de coisificação e fragmentação ${ }^{2}$ (MORIN, 2000), no qual a natureza não foi considerada do ponto de vista do seu valor intrínseco, senão apenas como fonte de recursos, fonte de riquezas, que ora parece finito. $\mathrm{O}$ "cálculo utilitário de conseqüências coletivas, sob o apelo individualista, não considerou na sua equação as questões ambientais" (FERNANDES, 2003).

\section{Superando a dicotomia entre sistemas ecológicos e sociais}

Não se sabe bem ao certo quando surgiu a dicotomia entre sistemas ecológicos e sociais. Uma corrente formada por ecologistas, predominantemente preservacionistas, aponta para o criacionismo ${ }^{3}$ como uma de suas principais causas. O criacionismo sugere literalmente que Deus criou o universo e depois o homem, a partir de sua imagem e semelhança, com autoridade para dominar outros seres vivos (animais e plantas), tal como se apregoa no Velho Testamento. Uma segunda corrente, composta por ecologistas políticos, aponta a civilização grega como um dos mais importantes motivos. A civilização grega é vista como um marco da história da humanidade por recontextualizar, redesenhar e recontar os fenômenos da natureza a partir da perspectiva antropocêntrica (deuses com figuras humanas), como tão bem ilustram as metáforas da Mitologia Grega (BUlFInCH, 2001). Ambas as correntes sugerem que o sistema social prevalece sobre o ecológico.

\footnotetext{
${ }^{2}$ Morin (2000), referindo-se a Descartes, Buffon, Marx e Bacon.

${ }^{3}$ Segundo o capítulo Gênesis, tratando das origens do mundo e da humanidade, calcula-se que a criação surgiu, aproximadamente, há 5.000 anos antes de cristo ( $A$ Bíblia de Jerusalém. Traduzida La Sainte Bible, edição de 1973, publicada sob a direção da École Biblique de Jerusalém. São Paulo: Paulus, 2001).
} 
Uma terceira corrente, que é formada por ecologistas, aponta para o evolucionismo como o principal marco a ter causado essa sobreposição (CAVALLI-SFORZA, 2003). Uma das principais teorias do evolucionismo baseia-se nos princípios da seleção natural darwiniana, afirmando que sobrevivem os membros mais fortes da espécie, ou melhor, os mais adaptados ao meio ambiente (DARWIN, 2002). Essa corrente, valendo-se da expressão darwinismo social, sugere que a competição prevalece sobre a cooperação e que esta sobreposição consiste na principal estratégia de sobrevivência numa economia de mercado. Surgem, então, as denominações recursos humanos e recursos naturais para designarem, respectivamente, indivíduos e natureza como se fossem elementos exclusivos da perspectiva econômica, utilitarista e produtivista (ROzZI, 1999).

Deveria haver uma ressignificação do que se convencionou chamar "recurso natural" (como se a biodiversidade pudesse ser valorada apenas pela lógica economicista). Entretanto, reconhece-se que recursos naturais e serviços ambientais têm funções e valores econômicos positivos (na perspectiva da Economia Ecológica) e que tratá-los como preço zero, como se faz muitas vezes na perspectiva utilitarista, seria um risco sério de exauri-los ou manejá-los insustentavelmente (ALIER, 2007).

Independentemente da origem dessa dicotomia, com a deflagração da problemática ambiental têm surgido outras leituras da interação dos sistemas sociais e ecológicos. Dentre essas leituras, o conceito de resiliência tenta representar a ligação e a relação de interdependência entre sociedade e natureza. $\mathrm{O}$ conceito de resiliência ${ }^{4}$ é utilizado pela tragédia dos comuns e por outras escolas para explorar, sobretudo, as ligações entre os processos ecológicos, sociais e institucionais, buscando fornecer meios para descobrir introspecções novas para a compreensão da inter-relação ambiente-sociedade. Na representação trazida nesse conceito, a ênfase afasta-se da evolução linear, movendose para um foco no processo, transcendendo os modelos simplistas de causa e efeito e da dicotomia ambiente $\mathrm{x}$ sociedade, para voltar-se para como os processos ligam o ambiente e a sociedade, em diferentes escalas espaciais e temporais. Essas introspecções contribuem para um enfoque mais apropriado para a compreensão de como as mudanças ocorrem dentro dos sistemas complexos (HOLLING; SANDERSON, 1996; BERKES; FOLKE, 1998; DAVIDSONHUNT; BERKES, 2003), como defendido na teoria geral dos sistemas ${ }^{5}$

Que se diga que a parábola da tragédia dos comuns, idealizada por Hardin (1968), transmite a impressão equivocada de que as políticas e instrumentos de gestão privada para a sustentabilidade são mais eficientes do que a gestão pública e comunitária, quando se trata de direitos estáveis de acesso e controle ou uso (apropriação) sobre a totalidade ou parte dos recursos. Hardin confunde acesso e uso livre com acesso e uso público. A coisa pública é entendida como um bem ou um serviço que pode ser planejado, portanto, factível de gestão, ora estatal (mediante governos ou organização pública), ora comunitário (por associações ou organizações não governamentais). Não se está colocando em cheque a apropriação privada ou seus méritos próprios; todavia, há necessidade de se resgatar outros modos de apropriação de recursos naturais, como estatal e comunitário.

A complexidade é, assim, também uma leitura da interação entre sociedade e natureza e postula princípios unificadores para essa relação, assim como para o entendimento dos problemas decorrentes que atravessam verticalmente o universo das ciências individuais, visando a integração e a unidade da ciência. Trata-se de uma maneira de conceber o mundo - a visão sistêmica do mundo - assim como de abordar e formular problemas. No plano da ciência, caracteriza-se por conceber todo objeto como uma totalidade complexa e/ou como um componente de tal. Admite a necessidade de estudar os componentes de um sistema; porém, não se limita a eles. Embora importantes as características das partes, o entendimento das propriedades sistêmicas é fundamental, principalmente em circunstâncias ambientais. Não se trata de um novo conhecimento, ou de novas informações, mas de um novo enfoque, a partir do

\footnotetext{
${ }^{4}$ A palavra "resiliência" tem origem no latim (resílio: retornar a um estado anterior). Resiliência é a propriedade pela qual a energia armazenada em um corpo deformado é devolvida quando cessa a tensão causadora da deformação elástica (HOUAISS; VILLAR, 2001). Adaptando-se à questão ambiental, ou a uma visão sistêmica, resiliência é a capacidade de um sistema de superar o distúrbio imposto por um fenômeno externo e manter-se inalterado. É a resiliência que determina o grau de defesa, ou vulnerabilidade, do sistema às pressões ambientais externas.

${ }^{5}$ Proposta por L. von Bertalanffy (1985), a Teoria Geral de Sistemas implica a análise da natureza dos sistemas e da inter-relação entre eles em diferentes espaços, assim como a inter-relação de suas partes. Ela ainda analisa as leis fundamentais dos sistemas. Um sistema que é uma união de várias partes é formado de componentes ou elementos.
} 
qual se tratam as informações e o conhecimento muitas vezes já construído. A visão sistêmica desvela nuances que só são visíveis a partir da visão complexa da interação do todo. A complexidade e a interdisciplinaridade não são, assim, um objetivo, mas resultados inerentes da sua aplicação enquanto enfoque (LAZLO, 1972). Além disso, trata-se de uma perspectiva paradigmática que, conforme postula Morin (2000), não se limita ao estudo de temas setoriais integrados, mas consiste na reforma do pensamento e da racionalidade científica, incorporando, inclusive, outros saberes. Por acentuar a natureza sistêmica do mundo natural e social, o sistemismo coloca em xeque a fragmentação tradicional de alguns ramos do conhecimento e sugere a sua integração.

Embora predominem estudos especializados e com uma visão ainda demasiadamente reducionista e descontextualizada, cada vez mais tem se tornado evidente que a maioria dos objetos com os quais tratamos - especialmente questões de cunho socioambientais -, são sistemas ou subsistemas multifacetados e, como tal, escapam do alcance de especialistas com visões excessivamente estreitas. Estamos aprendendo gradualmente que o melhor especialista é o que tem perspectiva interdisciplinar (JOLIVET; PAVÉ, 2000).

Nesse sentido, a problemática socioambiental, enquanto campo de pesquisa, emana da discussão acerca da fragmentação do conhecimento e da necessidade de ruptura do modelo disciplinar em favor de um modelo mais integrativo. A interdisciplinaridade ganha força mediante uma demanda advinda da própria realidade, do próprio objeto de pesquisa. A força de atração da visão interdisciplinar postula um novo tipo de ciência, norteado pelos modelos vivos e não mecânicos e, por isso, portador de mudança não só no âmbito cientifico (JANTSCH, 1995). Os sistemas ecológicos e os sistemas sociais funcionam baseados em relações binárias. Há uma circularidade dinâmica entre ambos. Aliás, o reducionismo e a fragmentação para entender determinado fenômeno vêm provocando crescentes disfunções nas inter-relações sistêmicas que ambos compõem. Portanto, os problemas mais significativos contemporâneos não serão resolvidos de maneira disciplinar, isto é, por especialistas. Muitos desses problemas tornaram-se problemas exatamente por terem sido tratados de maneira unidisciplinar. O desafio da interdisciplinaridade é desfazer essa fascinação que se tem pela especialização e, ao mesmo tempo, resgatar conhecimentos e sentimentos perdidos, reintegrando-os aos campos de saberes diversos e, assim, possibilitar a melhor compreensão e resolução dos problemas (MAXNEEF, 2005).

\section{Considerações finais}

A problemática socioambiental postula uma mudança de paradigma que tem como base de sustentação uma racionalidade alternativa aos grandes conflitos da sociedade moderna. Esses conflitos são traduzidos e resumidos pela difícil relação entre desenvolvimento econômico e preservação ambiental. A mudança de paradigma está no fato de inserir a sustentabilidade socioambiental como pré-requisito do desenvolvimento. A problemática socioambiental, por intermédio da visão sistêmica e atuação interdisciplinar, postula também uma mudança moral e ética a partir de uma fundamentação ecológica (DANSEREAU, 1999). É, por isso, uma utopia que vem junto com o novo paradigma da sustentabilidade. $\mathrm{O}$ desenvolvimento deve relevar os valores, as crenças e diferentes modos de vida, sobretudo de comunidades tradicionais, configurando-se numa proposta paradigmática não só de cunho científico como também de cunho cultural. Em outras palavras, é uma proposta de revisão das concepções culturais, vital aos fins da atualidade e do equacionamento da crise socioambiental em toda a sua complexidade.

Como a raiz dos problemas ambientais está na exploração da natureza sem critérios e motivada por valores de dominação e colonização, materializados na capacidade de posse econômica e consumo, a sua resolução depende de valores como a emancipação (em seu sentido político e como substantivo), como capacidade de reflexão política - como propõem os autores da escola de Frankfurt e Ramos (1989) -, convergência, a não-violência ativa e a coevolução, inerentes ao enfoque sistêmico e interdisciplinar, numa relação que é própria da natureza: a comunhão.

Conforme a mensagem de Morin e Kern (1995), o modelo ocidental-europeu desenvolvimentista não é capaz de perceber que a Terra está doente e precisa ser cuidada, e não dominada. Foi baseado na racionalidade econômica - desenvolvimento como sinônimo de crescimento econômico sustentado pela própria ciência econômica, e pela fragmentação e departamentalização do conhecimento - que esse modelo imprimiu ao processo civilizatório do 
planeta uma lógica de violência e dominação na qual tudo é condicionado ao economicismo. Encontrar senão o caminho perfeito de desenvolvimento, mas o melhor caminho fundamentado na convergência da diversidade, na fraternidade e no amor entre os homens e com a Terra é a aposta numa realidade invisível, imprevisível e improvável. É uma utopia que vem junto com o novo paradigma da sustentabilidade, a utopia da salvação da Terra. O imperceptível, assim como o surgimento da vida no planeta, apenas parece improvável. Não vemos a realidade que se esconde por traz da realidade que vemos. Desde a possível origem da vida em meio ao caos, até a atualidade, os diversos eventos históricos, as suas gêneses, o desenvolvimento e a efetivação do que convencionou chamar "era planetária", evidenciam, face à diversidade cultural da humanidade, a complexidade da vida no planeta e a multidimensionalidade das inter-relações, assim como

\section{Referências}

ALIER, J.M. O ecologismo dos pobres. São Paulo: Contexto, 2007.

ANTUNES, Carlos; JUQUIN, Pierre; KEMP, Penny; STENGERS, Isabelle; TELKAMPER, Wilfrid; WOLFF, Frieder Otto Ecosocialismo, uma alternativa verde para a Europa. Lisboa: Divergência, 1990.

BERKES, F.; FOLKE, C. Science, sustainability and resource management. In: ; _ . Linking social and ecological systems. Cambridge: Cambridge University Press, p. 342-361, 1998.

BULFINCH, Thomas. O livro de ouro da mitologia: a idade da fábula. Rio de Janeiro: Ediouro, 2001.

CAVALLI-SFORZA, Luigi Luca. Genes, povos e línguas. São Paulo: Companhia das Letras, 2003.

DANSEREAU, P. Uma preparação ética para a mudança global: prospecção ecológica e prescrição moral. In: VIEIRA, Paulo Freire; RIBEIRO, Mauricio A. (Orgs.). Ecologia humana, ética e educação. A mensagem de Pierre Dansereau. Florianópolis: APED, p. 299-370, 1999.

DARWIN, Charles. Origem das espécies. Belo Horizonte: Itatiaia, 2002.

DAVIDSON-HUNT, I. J.; BERKES, F. Nature and society through the lens of resilience: toward a human-in-ecosystem um predomínio da incerteza e da imprevisivibilidade que contrapõem a idéia de domínio seguro que, paradoxalmente, tem sustentado a cultura ocidental e o conceito de desenvolvimento linear.

Que essa mudança de paradigma leve-nos a um patamar não só de consciência dos problemas socioambientais a ponto de inverter o paradigma econômico e todos os que a ele deram origem, mas também nos faça capazes de olhar além de nós mesmos, ou seja, além de nossas ideologias, crenças, valores e aspirações. Que essa mudança leve-nos a um patamar em que sejamos capazes de fazer análises e auto-análises, não aprisionados na objetividade e suposta neutralidade das ciências como alimento do ego e dos interesses próprios. Um patamar onde predomine a sensibilidade capaz de dar alma a esses conceitos.

perspective. In: BERKES, F.; COLDING, J.; FOLKE, C. (Eds.). Navigating social-ecological systems. Building resilience for complexity and change. Cambridge: Cambridge University Press, p. 53-82, 2003.

FERNANDES, Valdir. Indústria, meio ambiente e politicas públicas em Santa Catarina. Florianópolis. 2003. Dissertação (Mestrado em Engenharia Ambiental) - PPGEA, Universidade Federal de Santa Catarina, 2003.

HARDIN, Garet. The tragedy of the commons. Science, v. 162, p. 1243-1248, 1968.

HOLLING, C. S.; SANDERSON, S. Dynamics of(dis)harmony in ecological and social systems. In: HANN, S. et al. (Eds.). Rights to nature. Washington, D.C.: Island Press, p. 57-85, 1996.

HORKHEIMER, Max. Eclipse da razão. São Paulo: Centauro, 2002.

HOUAISS, Antônio; VILLAR, Mauro de Salles Dicionário Houaiss da Língua Portuguesa. Rio de Janeiro: Objetiva, 2001.

JANTSCH, E. Interdisciplinaridade: os sonhos e a realidade. Tempo Brasileiro, v. 121, p. 29-42, 1995.

JOLLIVET, M.; PAVÉ, A. O meio ambiente: questões e perspectivas para a pesquisa. In: VIEIRA, P. F.; WEBER, J. (Orgs.). 
Gestão de recursos naturais renováveis e desenvolvimento: Novos desafios para a pesquisa ambiental. São Paulo: Cortez, p. 51-112, 2000.

KOTHARI, R. Environment, technology and ethics. In: ENGEL, J.R.; ENGEL, J.G. (Eds.). Ethics of environment and development. Tucson: The University of Arizona Press, p. 27-35, 1990.

KUHN, Thomas S. A estrutura das revoluções cientificas. São Paulo: Perspectiva, p. 13, 1996.

LASZLO, E.. The systems view of the world. New York: Braziller, 1972.

MATURANA, Humberto R.; VARELA, Francisco J. A árvore do conhecimento: as bases biológicas da compreensão humana. São Paulo: Athena, 2001.

MAX-NEEF, Manfred. Foundations of transdisciplinarity. Ecological Econonomics, n. 53, p. 5-16, 2005.

MERICO, Luiz. F. K. Introdução à economia ecológica. Blumenau: FURB, p. 30, 1996.

MORIN, E.; KERN, A.B. Terra pátria. Porto Alegre: Sulina, 1995 .
MORIN, Edgar. Ciência com consciência. Rio de Janeiro: Bertrand Brasil, 2000.

PRIGOGINE, Ilya; STENGERS, Isabelle. A nova aliança. Brasília: Ed. UnB, 1984.

RAMOS, Alberto Guerreiro. A nova ciência das organizações: uma reconceituação da riqueza das nações. Rio de Janeiro: Fundação Getúlio Vargas, 1989

ROZZI, Ricardo. The reciprocal links between evolutionaryecological sciences and environmental ethics. BioScience, v. 49, n. 11, p. 911-921, nov. 1999.

SANTOS, Boaventura de Sousa. A crítica da razão indolente. São Paulo: Cortez, 2000.

SERRES, Michel. O contrato natural. Lisboa: Instituto PIAGET, p. 16, 2000.

VON BERTALANFFY, L. General systems theory - a critical review. In: Open Systems Group (Ed.) Systems Behaviour. London: Harper \& Row, p. 59-80, 1985.

WMO-UNEP. Intergovernmental panel on climate change. Paris, February 2007. 